\title{
The Day After Tomorrow: Designing an Optimal Fiscal Strategy for Libya
}

\author{
Carlos Caceres \\ International Monetary Fund, U.S.A. \\ ccaceres@imf.org \\ Serhan Cevik \\ International Monetary Fund, U.S.A. \\ scevik@imf.org \\ Ricardo Fenochietto \\ International Monetary Fund, U.S.A. \\ rfenochietto@imf.org \\ Borja Gracia \\ International Monetary Fund, U.S.A. \\ bgracia@imf.org
}

\begin{abstract}
Libya is highly dependent on exhaustible and volatile hydrocarbon resources, which constitute the bulk of government revenues. Although resource wealth provides the means to promote socio-economic development, procyclical fiscal policies threaten macroeconomic stability as well as fiscal sustainability and intergenerational equity. This paper provides an assessment of the cyclically adjusted fiscal stance, analyzes fiscal sustainability according the permanent income framework, and simulates various fiscal policy rules with the objective of developing a rulebased fiscal strategy that would delink the economy from oil price fluctuations, improve the management of resource wealth, and safeguard macroeconomic stability. The empirical results suggest that an "enhanced" structural fiscal balance rule would provide the strongest anchor for policymaking, accommodating for output and/or commodity price shocks, though at the cost of relative complexity.
\end{abstract}

JEL Codes: E32, E62, H11, H62, O13

Keywords: Fiscal policy, fiscal sustainability, fiscal rules, natural resources, public financial management 


\section{INTRODUCTION}

Libya has one of the largest hydrocarbon reserves in the world, with proven crude oil reserves of 47 billion barrels and natural gas reserves of 53 trillion cubic feet as of end-2010. The hydrocarbon sector accounts for over 65 percent of GDP and 95 percent of government revenues. This high degree of dependency on hydrocarbon earnings, which are erratic, unpredictable, and eventually exhaustible, makes the Libyan economy vulnerable and complicates fiscal policy management. ${ }^{1}$ The extent of hydrocarbon dependency was highlighted during the revolution, when crude oil production collapsed from an average of 1.69 million barrels per day in 2010 to 0.48 million barrels in 2011, leading to a 62 percent fall in real GDP and a deterioration in fiscal accounts from a surplus of 8.9 percent of GDP in 2010 to a deficit of 18.7 percent in 2011. While the restoration of hydrocarbon production toward the preconflict level led to a temporary improvement in the fiscal balance to a surplus of 24 percent in 2012, the nonhydrocarbon primary deficit continued to deteriorate and the underlying fiscal position remains on an unsustainable path over the long term.

While Libya's vast hydrocarbon wealth provides the means to promote socio-economic development, the critical issue is effective management of resource revenues. First, though substantial, Libya's hydrocarbon reserves are being gradually depleted and, some day in the future, will come to an end. ${ }^{2}$ To prepare for that day, the government must run surpluses during periods of high hydrocarbon prices and invest those savings in alternative sources of wealth, such as financial assets and public investments that add to the economy's productive capacity. After the depletion of hydrocarbon reserves, these alternative sources of wealth could then be expected to generate a return that could make close the gap between a reasonable level of government spending and nonhydrocarbon revenues. Second, building buffers during oil price upswings that can be used during downswings can help insulate the economy against volatile oil prices, promote balanced and diversified economic growth, and improve intergenerational equity in the distribution of resource wealth. This is not, however, just a policy objective to be pursued over the very long term. While Libya accumulated overall fiscal surpluses thanks to high hydrocarbon prices, the nonhydrocarbon fiscal stance has deteriorated considerably over the past decade, especially considering the quality and composition of public expenditure.

In most developing countries, however, fiscal policy is not typically countercyclical - that is, adding to aggregate demand during downturns and withdrawing demand during upturns. Instead, fiscal policy tends to be procyclical - that is, exacerbating downturns and amplifying upturns in the economic cycle. Furthermore, the extent of procyclical behavior is particularly pronounced in resource-dependent countries (Kaminsky, Reinhart, and Vegh, 2004; Talvi and Vegh, 2005; Medas and Zakharova, 2009; Villafuerte, Lopez-Murphy, and Ossowski, 2010). Consequently, an overall fiscal balance is not a meaningful indicator of the underlying fiscal position, and it does not allow an appropriate assessment of fiscal policy behavior over the business cycle, especially in a resource-dependent economy like Libya. Considering the volatility of hydrocarbon prices, we present an analysis based on a cyclically-adjusted nonhydrocarbon balance as a share of nonhydrocarbon GDP and show that the fiscal policy stance had been procyclical and expansionary prior to the revolution.

Evaluating fiscal sustainability, let alone whether the policy stance is optimal, is not an easy task in a hydrocarbon-dependent economy, as the volatility of hydrocarbon revenues complicates

\footnotetext{
Commodity price oscillations tend to be large, long-lasting, and asymmetric. Therefore, it is difficult to forecast prices with a reasonable degree of confidence, even over the medium term, which complicates the task of macroeconomic management in resource-dependent countries.

2 At the pre-conflict rate of extraction and assuming no new discoveries, crude oil and natural gas reserves would last about 77 years and 52 years, respectively. In practice, however, the level of reserves is dynamic and depends heavily on exploration activity and the extent of new discoveries, as well as on market conditions and technological developments that affect the cost and efficiency of extraction.
} 
policymaking and data limitations make the analysis even more challenging in the case of Libya. ${ }^{3}$ Following the literature on fiscal sustainability in resource-rich countries, we utilize the permanent income hypothesis $(\mathrm{PIH})$, which limits government spending in a given year to the rate of return on the present value of future natural resource streams including financial assets accumulated until the depletion of resource reserves. The results of this exercise show that Libya's current and projected fiscal position, assuming no change in policies, is not sustainable over the long term and will lead to significant wealth erosion and undermine macroeconomic stability.

Although recent research has questioned the relevance of the PIH framework as a fiscal policy anchor in resource-abundant developing countries with infrastructure gaps and low levels of human capital, scaling-up of development expenditure needs to take into account the institutional and absorptive capacity of the economy. In other words, the pace of scaling-up of development spending may need to be tempered to ensure the efficiency of capital investment, to avoid the risk of inflationary pressures, real exchange rate appreciation and lower nonhydrocarbon output, and to be consistent with the need to accumulate precautionary savings against the volatility of hydrocarbon revenues. All in all, fiscal policy needs to play a more prominent role in macroeconomic stabilization, especially considering its impact on nonhydrocarbon sectors. Because the hydrocarbon sector is effectively exogenous to fiscal policy, the inflationary impact on aggregate domestic demand and the risk of the so-called "Dutch disease" materialize through the nonhydrocarbon sectors.

A fiscal framework anchored on fiscal rules and strong institutional arrangements could help boost the credibility in the government's ability to maintain macroeconomic stability and ensure long-run fiscal sustainability, while insulating the economy against the volatility of hydrocarbon resources. Fiscal policy rules have become a popular tool for improving demand management and enhancing policy credibility, especially in emerging economies; they impose long-lasting constraints on key fiscal indicators through numerical limits on debt, deficits, expenditures, or revenue, or on a combination of these. While the optimal design of a rule-based fiscal framework varies from one country to another, depending on policy objectives and institutional capabilities, the basic principles are to moderate procyclicality and to ensure fiscal sustainability. Libya has practically no debt and an abundant stream of hydrocarbon revenues over the foreseeable future, but government finances remain dependent on volatile oil prices and production. Moreover, beyond building buffers against shocks, Libya also needs to ensure intergenerational equity. Therefore, a credible fiscal policy anchor would delink the economy from oil price fluctuations, improve the management of resource wealth, and safeguard macroeconomic stability. This study simulates a number of numerical fiscal rules and analyzes their benefits and drawbacks for fiscal performance. The empirical results suggest that an "enhanced" structural fiscal balance rule would provide the strongest anchor for policymaking, accommodating for output and/or commodity price shocks, though at the cost of relative complexity.

Effective implementation of a fiscal policy rule requires an explicit mandate as well as supporting institutional arrangements. Transparent application of a well-designed and credible fiscal rule is necessary to strengthen fiscal governance and to ensure sustainability and intergenerational equity. In this regard, a critical feature is that the fiscal rule is intended for application on a permanent basis by successive governments. It therefore needs to be based on a firm statutory instrument - such as a constitutional provision - and supported by a number of institutional arrangements - such as a fiscal responsibility law, a robust system of public financial management (PFM), a complementary Treasury Single Account (TSA) at the Central Bank of Libya (CBL), and a top-down policy guideline over a multi-year horizon - to ensure the effective implementation and the consistency of fiscal policy objectives.

3 The dataset is drawn from the IMF's International Financial Statistics and World Economic Outlook databases and from the Central Bank of Libya. 
The remainder of the paper is structured as follows. Section 2 explains the methodology for decomposing nonhydrocarbon GDP into trend and cyclical components, and estimates the cyclically adjusted nonhydrocarbon primary budget balance in Libya. Section 3 provides an analysis of fiscal sustainability according to the PIH framework. Section 4 develops a rule-based optimal fiscal framework for Libya according to simulations of various fiscal rules, followed by concluding remarks, in Section 5 , with specific policy and reform recommendations for developing effective and transparent fiscal policies.

\section{MEASURING THE FISCAL STANCE}

The overall fiscal balance is a commonly used indicator of the impact of fiscal policy on aggregate demand, a country's financing need - or accumulation of assets - as well as of its underlying fiscal vulnerability. However, when there is a high degree of correlation between natural resource prices and fiscal performance, as is the case in Libya, the volatility of commodity prices could result in a misleading picture of the underlying fiscal position and possible structural imbalances in the domestic economy. Therefore, the nonhydrocarbon primary budget balance, factoring out interest payments and resource-based revenue including investment income, provides a better indication of the fiscal stance. ${ }^{4}$ Furthermore, since the actual fiscal balance reflects cyclical - or temporary - effects on the government budget, as well as structural - or permanent - influences, it is important to refine the measurement of the underlying fiscal position further by developing a cyclically adjusted nonhydrocarbon primary budget balance scaled by nonhydrocarbon potential GDP, which would reflect revenues and expenditures adjusted for the impact of the economic cycle. ${ }^{5}$ As such, the cyclically adjusted nonhydrocarbon primary budget balance represents the discretionary part of fiscal policy and measures the true extent of fiscal impulse in a country heavily dependent on resource-based revenues.

Decomposing GDP into trend and cyclical components is the first step in estimating the cyclically adjusted balance. There are various methods, none without shortcomings, for decomposing GDP into its trend and cycle components. In this paper, because of data limitations, we use the Hodrick-Prescott filter developed by Hodrick and Prescott (1997) to extract trend and cyclical components and estimate the output gap. ${ }^{6}$ The boom period led to an estimated swing of 56 percentage points in the nonhydrocarbon output gap from a negative reading of 16.1 percent in 2001 to a positive output gap of 38.7 percent in 2010 (Figure 2). The extent of deviation from the trend during the global commodity boom is also striking compared to the average positive output gap of 4 percent in the 1990s (or an average negative deviation of 1.7 percent during the period 1970-2005, for that matter).

Output gap estimates are subject to uncertainty, especially in natural resource-based economies with a fairly elastic supply of labor. First, countries heavily dependent on commodity exports as the primary source of income are subject to significant and frequent shocks, for both endogenous and exogenous reasons, making it difficult to identify business cycles. Second, the presence of expatriate workers makes the concept of the "natural rate of unemployment" less

\footnotetext{
Investment income is usually reinvested abroad and therefore does not influence domestic aggregate demand.

Automatic stabilizers - certain features of the taxation system (such as a progressive personal income tax) and some expenditure items (such as unemployment benefits) that adjust automatically to cyclical fluctuations in economic activity - are not expected to have a prominent role in Libya. 6 The Hodrick-Prescott filter removes low frequency variations and smoothes the GDP series to its stochastic trend, depending on the weight assigned to the linear time trend. If there is no noise, the series is fully informative and the weight $-\lambda-$ should be equal to zero. While a $\lambda$ of 100 is typically the choice for annual data in the empirical literature, Baxter and King (1999) argue that a value of around 10 is more reasonable, and Ravn and Uhlig (2002) recommend a $\lambda$ of 6.5 for estimations using annual data. After experimenting with a range of smoothing parameters, we find marginal computational differences in the empirical analysis and adopt a $\lambda$ of 100 . It should be noted that the Hodrick-Prescott filter is also susceptible to the end-point problem - the trend follows actual GDP more closely at the beginning and end of the estimation period than in the middle. The end-point problem in the case of Libya is particularly pronounced after the removal of sanctions and prior to the global financial crisis, which we deal with by extending the series through 2017, using projections.
} 
informative as to whether the economy is operating below or above its potential. Furthermore, the estimated increase in potential nonhydrocarbon GDP during the boom years may have been partly a result of large public-sector projects, and consequently not as sustainable as a productivitydriven improvement. Nevertheless, despite the empirical shortcomings, estimates of potential nonhydrocarbon GDP and the output gap are consistent with inflation dynamics and present a reasonable gauge of deviation from trend growth. ${ }^{7}$

In measuring the cyclicality of fiscal policy in Libya, we follow the empirical methodology outlined by Horton, Kumar, and Mauro (2009) and Abdih et al. (2010), and accordingly use the nonhydrocarbon primary budget balance, excluding interest spending and hydrocarbon revenues, scaled by nonhydrocarbon GDP. Because hydrocarbon revenues are dependent on the erratic behavior of oil prices, the cyclically adjusted nonhydrocarbon primary balance is also computed, using the elasticity of nonhydrocarbon revenues and primary expenditures relative to nonhydrocarbon GDP, to assess whether fiscal policy exacerbates economic fluctuations. In this analysis, we perform cyclical adjustment on total revenue and expenditures by using the aggregate elasticities of nonhydrocarbon revenues (assumed to be 1) and primary spending with respect to the output gap (assumed to be 0 ).

The fiscal balance moved from an average deficit of 2.7 percent of GDP a year in the 1990s to an average surplus of 15.7 percent in the 2000s. However, that was a result of the unprecedented increase in hydrocarbon revenues, and the nonhydrocarbon primary deficit deteriorated from 22 percent of nonhydrocarbon GDP in 2000 to 155 percent by 2010. Furthermore, the cyclically adjusted nonhydrocarbon primary deficit as a share of nonhydrocarbon potential GDP increased from 20.5 percent in 2000 to 185 percent by 2008 and, in the aftermath of the global financial crisis, to 225 percent in 2010. In other words, the fiscal impulse - measured by the change in the cyclically adjusted nonhydrocarbon primary balance as a share of nonhydrocarbon potential GDP - amounted to over 200 percentage points on a cumulative basis over this period.

The combination of positive changes in the output gap with positive fiscal impulse implies a procyclical fiscal policy stance. Using this methodology, we find that fiscal policy was procyclical prior to the global financial crisis when the Libyan economy experienced an unprecedented above-potential boom in non-resource sectors and, consequently, persistent inflationary pressures. After the crisis, the government adopted an expansionary fiscal stance, raising the cyclically adjusted nonhydrocarbon primary budget deficit to 225 percent of nonhydrocarbon potential GDP by 2010. Although we do not estimate the changes in the underlying fiscal position that resulted from shocks during the revolution, macro-fiscal developments point to a marked deterioration in 2012 and beyond, compared to the preconflict stance that was already unsustainable, mainly because of substantial increases in wages, subsidies, and other transfers. Therefore, while Libya can afford elevated current spending in the short term, unchanged fiscal policies will erode the country's wealth over the long term.

\section{ASSESSING FISCAL SUSTAINABILITY}

As natural resource reserves will eventually be depleted, it is necessary to achieve an appropriate balance between current and future consumption. The standard PIH framework, based on the work of Friedman (1957), has become a popular methodology for assessing the sustainability of public finances in countries with vast hydrocarbon reserves. In this paper, we use the computational approach outlined by Barnett and Ossowski (2002) to estimate Libya's total

\footnotetext{
For example, consumer prices increased at annual rate of 4.4 percent, on average, during the period 2004-08, with inflation peaking at 10.4 percent in 2008. Although this was partly a result of the increase in international prices, the main factor pushing both tradable and nontradable consumer prices higher was the procyclical, expansionary fiscal policy stance that amplified the economic cycle during the global commodity boom.
} 
hydrocarbon revenue until the depletion of hydrocarbon reserves as well as the net present value of hydrocarbon-related revenue, which is taken to be a financial asset generating a permanent income. ${ }^{8}$ The estimated income stream is then used to determine the optimal growth path of real per capita government expenditure, without undermining the long-term financial position, in the following form:

$$
P V(S)=\bar{s} \sum_{i=1}^{\infty}\left(\frac{1+n}{1+r}\right)^{i}=\bar{s}\left(\frac{1+r}{r-n}\right)
$$

where is a sustainable level of real per capita government spending, is the growth rate of population, and is a discount rate (which in this exercise is proxied by an average real interest rate); the intertemporal government budget constraint is defined by the sum of current value of government's assets, the present value of nonhydrocarbon revenue over time, and the present value of hydrocarbon revenue before depletion. Assuming that nonhydrocarbon revenues grow at the same rate as nonhydrocarbon GDP, the present value of nonhydrocarbon revenues per capita can be expressed in the following form:

$$
P V(N H)=n h \sum_{i=1}^{\infty}\left(\frac{1+n}{1+r}\right)^{i}\left(\frac{1+y}{1+n}\right)^{i}=n h\left(\frac{1+r}{r-y}\right)
$$

where is nonhydrocarbon revenue per capita and is the growth rate of real nonhydrocarbon revenues, which must be lower than the discount rate for the present value of nonhydrocarbon revenues to be finite. Likewise, we can write the present value of hydrocarbon revenue per capita as the following:

$$
P V(H)=h \sum_{t=0}^{T}\left(\frac{1+n}{1+r}\right)^{t}\left(\frac{1+\theta}{1+n}\right)^{t}
$$

where is hydrocarbon revenue per capita, is the growth rate of real hydrocarbon revenues, and is the number of years before hydrocarbon reserves are expected to be depleted. Accordingly, the government budget constraint becomes the following function:

$$
P V(S)=P V(N H)+P V(H)+F=n h\left(\frac{1+r}{r-y}\right)+h \sum_{t=1}^{T}\left(\frac{1+\theta}{1+r}\right)^{t-1}+F
$$

where is the present value of financial wealth. In a steady state of long-term fiscal sustainability, the present value of government spending must be equal to the sum of current value of government's assets, the present value of nonhydrocarbon revenue over time, and the present value of hydrocarbon revenue before depletion. In other words, with a fraction of hydrocarbon revenues invested in financial assets until the depletion of proven hydrocarbon reserves, the government needs to smooth the per capita spending profile according to the return on the accumulated financial wealth.

The above-outlined analytical framework is sensitive to parameters such as population growth, real rate of return on financial assets, and the future path of crude oil prices, but the PIH model still provides a simple quantitative benchmark that can guide fiscal policy management. Adhering to the implied target for nonhydrocarbon primary budget balance would help maintain a countercyclical stance that would support monetary policy objectives under the pegged exchange rate regime and would ensure consistency with long-term fiscal sustainability. ${ }^{9}$ Based on the above-outlined

\footnotetext{
A more conservative approach is the "bird-in-hand" strategy that limits government spending according to the return on savings already accumulated in a sovereign wealth fund system. This stringent option, however, may not be appropriate to developing countries like Libya because of their sizable capital expenditure needs and low level of accrued financial assets.

9 The PIH framework is widely applied in economies that, like Libya's, are hydrocarbon dependent. Cevik (2011), for example, provides a similar analysis for the United Arab Emirates.
} 
methodology, the government should smooth consumption out of hydrocarbon income over time, in line with the present value of expected hydrocarbon wealth. ${ }^{10}$ Assuming constant real per capita government expenditure that delivers a constant real per capita annuity after the depletion of hydrocarbon resources and crude oil prices at an average of $\$ 80$ per barrel, the nonhydrocarbon primary budget deficit is estimated to be 12.5 percentage points of GDP higher than its equilibrium value in 2013, with the gap increasing to 20 percentage points by $2018 .^{11}$

Conceptually, the standard PIH framework does not distinguish between domestic investments and foreign assets, even though investments abroad and at home have very different implications for the economy. Recent research has also questioned the relevance of the standard PIH model as a fiscal policy anchor in resource-rich developing countries with infrastructure gaps and low levels of human capital (Baunsgaard, Villafuerte, Poplawski-Ribeiro, and Richmond, 2012). Accordingly, with a modified PIH approach excluding development expenditure that may yield a return on investment equal to the discount rate used in the annuity calculations, we estimate that the nonhydrocarbon primary deficit is 3.4 percentage points of GDP below its equilibrium value in 2013 and remaining at around 10 percentage points below the estimated equilibrium threshold over the medium term. While this implies abundant fiscal space to accommodate scaling-up of development expenditure, it does not take into account the impact of development spending on growth and the institutional and absorptive capacity of the economy. In other words, the pace of scaling-up of development spending may need to be tempered to ensure the efficiency of capital investment and to avoid the risk of inflationary pressures, real exchange rate appreciation and lower nonhydrocarbon output. Furthermore, in light of the need to build precautionary savings, such frontloading of expenditure would make the economy more vulnerable to the volatility of hydrocarbon revenues. Therefore, as proposed by Berg, Portillo, Yang, and Zanna (2012), a "sustainable investing" approach would gradually scale up development expenditure in line with institutional and absorptive capacity constraints, and would minimize the impact of volatile hydrocarbon earnings on the domestic economy.

The results indicate the need for fiscal rebalancing to safeguard long-term sustainability and ensure intergenerational equity in the distribution of the country's resource wealth, although the conventional PIH framework does not account for the possibility that the resource base could be extended and broadened through technological developments and the exploitation of probable reserves. Accordingly, a wider resource base would extend the production horizon and raise the sustainable nonhydrocarbon primary deficit. Nevertheless, with the cyclically adjusted nonhydrocarbon primary budget deficit running well over 200 percent, these results point to a need for fiscal adjustment to ensure long-term sustainability, improve intergenerational distribution of resource wealth, and prevent over-dependency on hydrocarbons.

The results of our analysis show that Libya needs a higher rate of public savings to forestall a sharp fiscal adjustment over the long term. Unless the economy is diversified to create additional sources of revenue before the depletion of hydrocarbon resources, the contraction of fiscal revenue will be steep and will significantly constrain expenditure at that time. Although the optimal consumption path determined according to the PIH provides a robust point of reference for fiscal policymaking, the volatility of oil prices and greater uncertainty about future hydrocarbon revenues require additional - precautionary - savings (Leland, 1968; Bems and Carvalho Filho, 2009). Furthermore, based on a stylized model of optimal precautionary saving and investment under uncertainty, Cherif and Hasanov (2012) show that policymakers need to build up precautionary savings in case the economy is hit by a negative and persistent income shock. While larger fiscal buffers, accumulated, for example, during periods of higher oil prices, would reduce the need

\footnotetext{
10 If population growth is different from zero, the optimal consumption path would require the use of a per capita permanent income rule as used here. Other rules are constant real wealth or constant real wealth per capita.

11 The calculations assume the real rate of return on financial assets, inflation, and population growth of 5 percent, 2 percent, and 1.8 percent, respectively. Crude oil price projections are based on the latest 2013-18 profile published in the IMF's World Economic Outlook and assumed to increase at 2 percent thereafter.
} 
for sharp fiscal tightening during downturns, policymakers should also focus on improving productivity in the tradable sector and reducing volatility through diversifying this sector. This would lower precautionary saving needs, increase investment, raise consumption, and improve welfare. Finally, in addition to intergenerational equity and sustainability considerations, the fiscal stance also needs to be guided by the objective of maintaining macro-financial stability, as the pegged exchange rate regime constrains the central bank's ability to conduct countercyclical monetary policy and thereby puts the onus of stabilization on fiscal policy.

\section{BUILDING A RULE-BASED FISCAL FRAMEWORK}

Libya's budget formulation and preparation process is not transparent, and the budget does not provide information about the key macroeconomic parameters such as real GDP growth and inflation. The budget is also fragmented - driven by a mechanical and incremental approach - and follows two separate and uncoordinated processes at both the central and line ministry levels. The current budget system does not provide adequate tools to achieve a significant degree of fiscal adjustment, especially in view of a cyclically adjusted nonhydrocarbon primary budget deficit of over 200 percent of GDP. Taking into account the country's hydrocarbon wealth and large infrastructure and reconstruction needs, the adoption of a rule-based, transparent medium-term fiscal framework would provide a stable anchor for stabilization and intergenerational equity objectives and support the CBL's commitment to the pegged exchange rate regime.

The volatility of economic activity and fiscal aggregates in a hydrocarbon-dependent economy increases the merits of rule-based fiscal policy. Fiscal policy rules - a formal constraint on discretionary fiscal policy, typically defined in terms of a numerical target for fiscal performance - have become a popular tool for avoiding procyclicality and enhancing policy credibility, especially in emerging economies: the number of countries adopting national or supranational fiscal rules has increased from only five in 1990 to 81 in $2012 .{ }^{12}$ Fiscal policy rules place constraints on discretionary policies through procedural and numerical limits on fiscal aggregates such as the structural budget balance, spending, or indebtedness in proportion to GDP (Ter-Minassian, 2006; Filc and Scartascini, 2007). Although the optimal design and implementation of a rule-based medium-term fiscal framework varies from one country to another, depending on fiscal policy objectives and institutional capabilities, the basic principles are to constrain pressures to overspend, moderate procyclicality, and ensure long-term fiscal sustainability and equitable intergenerational use of the hydrocarbon wealth (Kumar et al., 2009). In the case of Libya, the analysis presented in this paper shows that the fiscal policy stance, with a high and volatile level of spending, poses a threat to these objectives. Without a fiscal policy rule designed to smooth out volatility and to ensure a countercyclical stance, the behavior of government spending would continue to be highly erratic and undermine macroeconomic stability, long-term fiscal sustainability as well as intergenerational equity.

While macroeconomic policymaking is a balancing act among different objectives, the ability of procedural and numerical fiscal rules to attain main policy goals differs significantly. Furthermore, policy priorities may change over time, once past policies have succeeded in achieving certain objectives (e.g., reducing public debt or reducing volatility of fiscal spending), providing the rationale for changing the fiscal rule at certain point in time. Figure 1 illustrates the "tradeoffs" involved in alternative fiscal rules vis-à-vis four main policy objectives. The shaded area within the diamond represents the effectiveness of each fiscal rule in maintaining a sustainable debt level, responding to shocks, smoothing fluctuations of key fiscal aggregates, and ensuring transparency, easy monitoring, and proper guidance. Trade-offs among various

12 Budina et al. (2012) provide country-specific information on fiscal policy rules as well as key supporting features such as independent monitoring institutions 
policy objectives inevitably exist. For example, the more flexible a rule - i.e., the more it allows for countercyclicality - the less likely that it will be simple and easy to monitor, as illustrated by the comparison between structural and augmented growth-based rules on one hand, and deficit ceiling or balanced budget rules on the other. The flexibility-credibility trade-off adds another layer of difficulty to the design of fiscal policy. All in all, as argued by Kopits and Symansky (1998), an ideal fiscal rule should be: well defined as to the selected variable, institutional coverage, and escape clauses; highly transparent; adequate with respect to the specified policy objective; consistent internally as well as with other macroeconomic policies; sufficiently simple in the eyes of the public; flexible enough to accommodate cyclical fluctuations and exogenous shocks; enforceable in the given environment; and supported by efficient policies rather than one-off measures. Given the politically induced bias toward increasing expenditures in the short run, a transparent and well-designed fiscal policy rule constitutes a compelling option for decoupling government spending - and the nonhydrocarbon budget balance - from the volatility of hydrocarbon revenues.

\section{Figure 1.}

Tradeoff Between Alternative Fiscal Rules and Four Main Policy Objectives

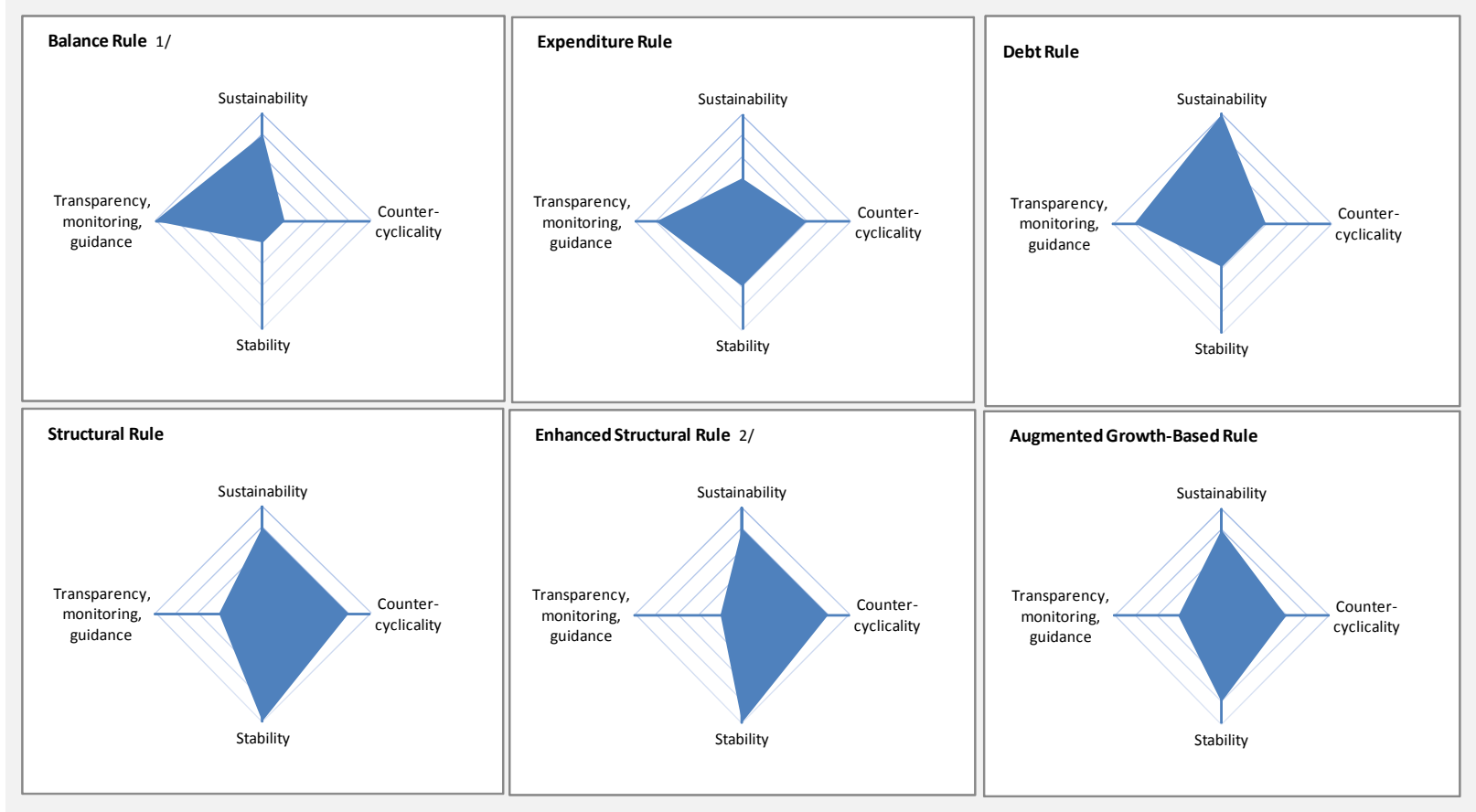

1/ A maximum of 5 is assigned to each criterion.

2/ The use of a balance budget rule is just for simplification purposes. All arguments hold for nominal budget rules (i.e., a deficit ceiling of 1 percent of GDP, etc.). The enhanced structural balance rule adjusts for changes not only in output gap - as in the structural balance rule - but also in commodity prices with regard to their long-term trend.

Source: Authors' calculations.

Balanced budget rules establish a simple framework in which to evaluate compliance and retain fiscal sustainability properties. Balanced budget rules are closely linked to the debt/asset accumulation ratio, so they normally perform well in terms of sustainability, unless off-budget operations are significant. Nevertheless, they are likely to be procyclical and promote volatility of main fiscal aggregates. For example, while the balanced budget rule limits the (nonhydrocarbon) deficit during economic downturns, it does not prevent fiscal policy from being procyclical during economic upturns. ${ }^{13}$ Finally, balanced budget rules do not behave well in maintaining stability. Under the deficit ceiling rule, fluctuations in revenues due to the business cycle or macroeconomic

13 It should be noted that this conclusion holds independently of the shape of the business cycle. 
shocks are followed by corresponding adjustments in expenditures, which make public spending very volatile.

Expenditure rules provide operational guidance and are easy to monitor, but also have limitations. In practice, once the expenditure target is clearly defined, expenditure rules provide operational guidance to fiscal policy and improve accountability. Nevertheless, risks in implementation remain. For example, limits on total expenditure may lead to across-the-board or low-quality adjustments; limits on a particular category of expenditure (e.g., current) may shift the source of indiscipline to the categories not covered by the rule (i.e., creative accounting) reducing its credibility. Moreover, expenditure rules are not linked directly to the debt ratio without consideration of the revenue side. Therefore, their usefulness in meeting a debt target is limited. But the most positive characteristics of expenditure rules are their ability to promote (at least, in some cases) countercyclicality and to reduce the volatility of public spending. Under the expenditure rule, fiscal policy could become countercyclical: when output is above potential, the public-spending-to-GDP ratio decreases; the reverse occurs when output falls below potential. Moreover, the expenditure rule, when fully enforced, reduces the volatility of public spending.

A structural balance rule provides a straightforward mechanism for allowing flexibility to respond to shocks. This rule allows for temporary deviations in the overall balance from its medium-term target according to cyclical developments. In particular, the rule can allow full operation of automatic stabilizers, calling for larger deficits (or lower surpluses) when the output gap is negative and requiring smaller deficits (or higher surpluses) when the output gap is positive. Net debt/asset accumulation is allowed to decline (or rise) as necessary in response to changes in the output gap. The structural balance rule only allows for automatic stabilizers, but changes in the parameters could increase the variation of the overall balance with the economic cycle, to allow for discretionary (but guided) countercyclical policy. In terms of stability, a structural balance rule smoothes the spending pattern by absorbing part of the spending fluctuations associated with unexpected macroeconomic shocks. However, greater response to output shocks may come at the expense of transparency and ease of monitoring. ${ }^{14}$ The structural balance rule can be enhanced to allow for an adjustment of fluctuations in commodity prices that impact export revenues. The socalled "augmented structural balance rule" addresses the basic issue of the uncertainty with regard to commodity-based revenues (as in the case of, for instance, Chile). The rule targets a mediumterm balance level, which could fall below that level when the commodity revenue in a given year is below its average long-run level and vice versa. ${ }^{15}$ Therefore, in the case of a commodityexporting country, the structural balance rule shows a stronger performance in terms of stability by adjusting for an additional source of volatility in main fiscal aggregates.

The augmented growth-based balance rule mimics the structural balance rule, but introduces some adjustments to avoid relying on output gap estimates. This rule sets a medium-term target for the overall balance. It replaces the output gap with the difference between actual and longterm growth. The balance can then be lower than the medium-term target in years when economic growth is below trend, while a higher balance is required in years when actual growth is faster than the trend, all other things being equal. The augmented part of the rule responds to the fact that the rule also allows for gradual adjustment back to the medium-term target. In this way, the rule avoids the need for an unrealistic large adjustment in any single year, while promoting convergence back to the medium-term target and allowing countercyclical policy (similar to the structural balance rule). All this is achieved without requiring estimates of the output gap, which is normally uncertain and subject to frequent revisions. On the other hand, the effectiveness of a debt/asset accumulation rule in terms of debt sustainability may come at the expense of weak countercyclical properties

\footnotetext{
14 Issues remain in terms of practical design, monitoring, and implementation. In practice, monitoring the performance of the rule requires precise dating of the cycle, which involves a degree of judgment. In addition, because the length and level of peaks and troughs of any cycle are unknown until the cycle is complete, the performance of the rule is only fully tested ex-post.

The rule can be implemented with a notional fund, where any windfall from an increase in hydrocarbon revenues above its target is saved, which can then be used when hydrocarbon revenues fall.
} 
and limited ability to minimize the volatility of main fiscal aggregates. Moreover, although debt/ asset accumulation rules respond directly to sustainability problems, they do not provide enough guidance when debt is below its ceiling. Short-term discipline may not be ensured because policy slippages are only reflected, with a lag, in debt/asset accumulation ratios.

In practice, approaches to assessing the effectiveness of alternative fiscal rules have been mostly ad hoc and qualitative. Because much of the interest in fiscal rules has been prompted by the need for achieving or maintaining long-term fiscal sustainability, the choice of a fiscal rule has been mostly based on its impact on public debt dynamics. Consequently, debt sustainability exercises have become a key element of assessing fiscal rules in Fund documents. However, as noted above, fiscal sustainability is only one objective for selecting a fiscal rule. Other policy objectives such as promoting macroeconomic stability and countercyclical policy should be incorporated in the process of selecting a fiscal rule in a more standardized way. Similarly, the treatment of uncertainty in the traditional debt sustainability analysis is rather limited. Although it comprises some sensitivity analysis of debt dynamic based on standardized shocks, it is not country-specific, limiting the scope of the analysis. Therefore, in practice a standardized approach to assessing the effectiveness of fiscal rules is not yet available.

\section{Box 1.}

Analytical Definitions of Simulated Fiscal Rules

Expenditure rule dictates the rate of growth in budgetary expenditure, normally in real terms. In simulations, it is fixed at a predetermined level, equal to the long-run average rate of real GDP growth. In practice, the rolling average of real GDP growth recorded in previous periods can also be used. Although an expenditure rule - imposed as a ceiling on nominal or real expenditure growth - is operationally simple and provides clear guidance on how to adjust the fiscal stance, it requires a reliable medium-term framework to avoid large deficits and deterioration in the net asset position due to persistently lower revenue generation.

Structural balance rule links the budget balance in any given year to the medium-term balance target, adjusted for changes in the output gap. Formally, $b_{t}=b^{*}+a y_{t}^{G}$, with $a>0$, where $b_{t}$ is the budget balance in the current year, $b^{*}$ is the medium-term balance target, $a$ is the semi-elasticity of the budget balance with respect to the output gap, and $y_{t}^{G}$ is the output gap in the current year. No discretionary countercyclical policy is allowed when $a$ is set to reflect automatic stabilizers only. However, if countercyclical policy is desired, the parameter $a$ could be set higher than the semi-elasticity of the budget balance relative to the output gap. The cyclically adjusted nonhydrocarbon fiscal deficit rule would avoid procyclical policies and ensure sustainability. Under this rule, spending is budgeted ex-ante in line with the structural level of revenues that would be achieved if the economy were operating at full potential. Although it would support fiscal discipline, a structural fiscal balance rule is operationally more challenging in a hydrocarbon-based economy.

Enhanced structural balance rule links the budget balance in any given year to the medium-term balance target adjusted for changes in the output gap, and commodity price deviations from their long-term trend. Formally, $b_{t}=b^{*}+a y_{t}^{G}+c\left(p t-p^{*}\right)$, with $a>0$ and $c>0$, where $p_{t}$ is the actual commodity price, and $p^{*}$ is the long-term price of this commodity. In effect, the parameter $c$ plays the same role as the parameter $a$ in response to commodity price shocks instead of output shocks. In practice, this rule is akin to a rule keeping the cyclically-adjusted non-oil balance at a constant level $b^{*}$. This target can be set to ensure long-term fiscal sustainability and intergenerational equity, for instance, by using the PIH model.

Augmented growth-based balance rule aims to broadly mimic a structural balance rule, but makes some adjustments to avoid relying on output gap estimates, which in some cases are uncertain and subject to revision. The rule first replaces the output gap with the difference between actual and long-term growth. To promote countercyclicality and avoid requiring an unrealistically large adjustment in any single year, the rule also includes a term that smoothes the adjustment from any deviation from the previous year's medium-term overall balance target. In other words, this term delays the adjustment of the balance back to target. Formally, $b_{t}=b^{*}+a\left(g_{t}-g^{*}\right)$ $+\tau\left(b_{t-1}-b^{*}\right)$, with $a>0$ and $0<\tau<1$, where $a, b_{t}$, and $b^{*}$ are defined as for the structural balance rule and $\tau$ is the pace of adjustment when the overall balance in the previous year, $b_{t-1}$, is away from the medium-term target $b^{*}$. A smaller coefficient $\tau$ implies a faster correction. 
There is no one-size-fits-all fiscal rule that would work always and everywhere, because the effectiveness of rules depends on institutional factors. The efficacy of fiscal policy rules can vary considerably across countries, depending on the target variable, the initial conditions, the method of implementation, and the type of shocks that the economy experiences, among other factors. Furthermore, various approaches in the literature to assess the performance of alternative fiscal policy rules are often ad-hoc and qualitative, and do not take into account the uncertainties under which policymakers operate. Therefore, to account for country-specific factors and the effect of uncertainty in fiscal projections, we employ an analytical framework utilizing stochastic simulation methods. This approach illustrates how different fiscal rules perform, with respect to the objectives mentioned earlier, in response to macroeconomic shocks calibrated for each specific country. By fitting stochastic shocks to the historical data of a given country, it helps the fiscal economist discuss the appropriate level of risk that the authorities might be willing to take.

The joint distribution of shocks is calibrated to fit the statistical properties of historical data using an unrestricted vector autoregressive (VAR) model. ${ }^{16}$ The study methodology is an extension to the algorithm proposed by Celasun, Debrun, and Ostry (2006): it describes the co-movements of the output gap, interest rates, and exchange rates, and provides estimates of the conditional variances and covariances of the shocks. ${ }^{17}$ We can formally express this as the following equation:

$$
Y_{t}=\Gamma_{0}+\Sigma_{k} \Gamma_{k} Y_{t-k}+\xi_{t}
$$

where is a vector of endogenous variables, $i$ is the domestic real interest rate, $\alpha$ is the output gap, $z$ is the log of the real effective exchange rate, are matrices of coefficients, and is a vector of wellbehaved error terms. The variance-covariance matrix of residuals characterizes the joint statistical properties of the contemporaneous shocks affecting fiscal aggregates. The VAR generates forecasts of $Y$ consistent with the estimated structure of the shocks. As shocks occur each period, the VAR produces joint dynamic responses of all elements in $Y$. The model is not sensitive to the ordering of variables in the VAR. For each simulated constellation of shocks, projections for growth, the output gap, the real interest, and the real exchange rate are generated via Monte Carlo simulations. Similarly, projections for fiscal aggregates dictated under each fiscal rule are constructed for each year of the forecasting horizon. Through repeated simulations of random shocks, frequency distributions of the balance ratio and the net debt/asset accumulation ratio can be obtained for each fiscal rule and year of projection. These are then used to draw fan charts of the fiscal aggregates, presented in Figure 2, depicting confidence bands for varying degrees of uncertainty around the median projection. ${ }^{18}$

Exogenous factors can also play an important role in driving the behavior of budgetary aggregates. In a hydrocarbon-exporting country, budgetary aggregates are significantly influenced by the changes in crude oil and natural gas prices, which are generally determined exogenously by global demand and supply conditions regardless of Libya's own production decisions. In general, these price shocks could also have important effects on the endogenous variables mentioned above (such as the output gap and the real effective exchange rate). To take into account the possibility of exogenous shocks, we extended the model presented in Equation (5), so that the endogenous

\footnotetext{
16 For a complete description of the methodology, see Caceres and Ruiz-Arranz (2010).

17 Since the objective of this exercise is to simulate the implementation of alternative fiscal rules, we depart from the Celasun, Debrun, and Ostry algorithm in that we do not incorporate a fiscal reaction function. Instead, we simply impose each alternative rule as a predetermined fiscal behavior to be binding and met every year of the forecasting horizon.

18 Fan charts summarize risks to fiscal variables dynamics by representing the frequency distribution of a large sample of paths generated by means of stochastic simulations. Different colors delineate deciles in the distribution of fiscal variables, with the zone in dark blue representing the 20 percent confidence interval around the median projection and the overall colored cone, a confidence interval of 90 percent.
} 
vector is not only affected by its own past, but also by a vector of exogenous variables (and its past behavior). ${ }^{19}$ Formally,

$$
Y_{t}=\Gamma_{0}+\sum_{k} \Gamma_{k} Y_{t-k}+\sum_{j} \Upsilon_{j} Z_{t-j}+\xi_{t}
$$

where all terms are as in Equation (5) and, in addition, are matrices of coefficients. These simulations help us to assess how effectively different fiscal rules achieve fiscal policy objectives in response to various shocks, based on their historical pattern. This methodology allows for a comparative analysis of the responses of different fiscal policy rules subject to the inherent uncertainty derived from macroeconomic shocks.

The accuracy of simulation results derived from this approach is subject to certain limitations. First, the distributions generated throughout the simulation period are based on historical data, assuming that the universe of possible shocks that are likely to arise in the future is similar to that observed during the estimation period. It is therefore essential that the estimation period in simulations is representative of the economic cycle. For instance, if only a very short and stable period is used to estimate the distributional structure of economic shocks, then the simulations may underestimate the underlying (larger) risks in the economy. Conversely, when long time series are available, the presence of important structural breaks in the series could pose some risks to this methodology. In other words, there could be, in some cases, a tradeoff between the length of the available series and the accuracy and stability of the estimated distributional structure. A second potential caveat in this approach is the absence of feedback loops between the budgetary aggregates and the macroeconomic shocks. ${ }^{20}$ The macroeconomic shocks are endogenously determined, and then are allowed to impact the budgetary aggregates. However, the latter do not have an explicit impact on the macroeconomic shocks throughout the simulation horizon. ${ }^{21}$

For Libya, we compare three types of fiscal policy rules: an expenditure rule, an augmented growth-based balance rule, and a structural balance rule, which can be further "enhanced" to account for the volatility of oil prices. As presented in Figure 7, the simulation analysis shows that fiscal rules based on the cyclically adjusted balance are superior in dealing with output and/ or commodity price shocks. In particular, the enhanced structural balance rule would entail the narrowest band for primary spending in response to such shocks. Compliance with the fiscal rule, in this case, requires relatively low policy variability, while it allows for automatic deviations from the target to accommodate shocks. The enhanced structural balance rule is akin to maintaining the cyclically adjusted nonhydrocarbon balance as a share of nonhydrocarbon GDP constant over time. This medium-term "structural target" level can be derived from the PIH model used in assessing fiscal sustainability and intergenerational equity. ${ }^{22}$ In practice, however, cyclical adjustment requires great care in policymaking as well as analytical capabilities to estimate the output gap and, for the enhanced variant of the rule, the equilibrium price of crude oil; these requirements add complexity to the implementation of a structural balance rule.

\footnotetext{
19 In the particular case of the simulations presented in this paper (Figure 2), corresponds to the (log) price of crude oil.

20 The simulations presented in this paper are calibrated in such a way that the different rules allow the full operation of automatic stabilizers. However, caution is warranted when the calibration of the rules leads to a response substantially different from that implied by automatic stabilizers.

21 The interaction between fiscal policy and macroeconomic shocks varies across countries and time, but also depends on the existing macroeconomic conditions at a given point in time. In other words, the 'fiscal multiplier' effect varies from country to country, but also within a given country, as the magnitude - and even the sign - of this effect might change through time. In addition, such effect might present important non-linearities which are difficult to estimate empirically. Once again, in the absence of information regarding these effects, and given that the latter are likely to change after the introduction of a fiscal rule, we think that omitting them from the simulations might be a safe option. After all, one of the objectives of the simulation toolkit is simply to allow the comparison of different fiscal rules in a very agnostic way.

22 The fiscal policy target could be reviewed, say, every four to five years in view of macroeconomic developments, structural changes, and policy experience. However, such revisions should not be so frequent as to undermine the credibility of the fiscal policy framework.
} 
Fiscal rule simulations for Libya show that under the vast majority of possible shocks, net asset accumulation follows a downward trend over time. ${ }^{23}$ An augmented growth-based balance rule yields the narrowest spectrum for fiscal balance (or net accumulation of financial assets), while structural balance and expenditure rules imply a wider - albeit, in most cases, still declining - distribution for net debt/asset accumulation. This is because the selected deficit target in these illustrations (zero percent of GDP - that is, a balanced budget over the economic cycle) is consistent with an upward path for asset accumulation in the absence of shocks. Finally, the primary expenditure paths under the different rules suggest that the 'fiscal effort' required in implementing these rules is similar for the balance rule variants, but slightly higher for the expenditure rule. Despite its simplicity, transparency, and ease of implementation, the expenditure rule is not anchored within a fiscal sustainability framework. Furthermore, expenditure rules provide no guidance for the revenue side of the budget and consequently fail to constrain discretionary policies that lead to the deterioration of the fiscal position. For example, revenues might be allowed to decline during an economic downturn, but then they might not rise during an upturn, possibly because of discretionary fiscal policies. In the case of a hydrocarbon-dependent economy like Libya, however, if the structural balance rule proves too complex to implement in the near term, despite its conceptual superiority, an expenditure rule that includes capital spending could provide a transitional framework until a structural balance rule is introduced.

Transparent application of a well-designed and credible fiscal policy rule is necessary to strengthen fiscal governance and to ensure fiscal sustainability and intergenerational equity. Rogoff (1990) shows that electoral cycles cause myopia, induce election largesse, and reduce interest in addressing structural deficits. Furthermore, as argued by Debrun and Kumar (2007), the "common-pool" problem may aggravate the spending bias as competing demands get accommodated in the policymaking process while their fiscal impact is not fully internalized. Accordingly, a critical feature of a fiscal rule is that it is intended for application on a permanent basis by successive governments. It therefore needs to be based on a firm statutory instrument - such as a constitutional provision - and supported by a number of institutional arrangements such as a fiscal responsibility law, a robust PFM system, a complementary TSA at the CBL, and a top-down policy guideline over a multi-year horizon - to ensure the effective implementation and the consistency of fiscal policy objectives. While formal sanctions can be imposed to maintain strict standards of compliance and transparency, a well-anchored fiscal rule could still incorporate an explicit escape clause that accommodates a temporary deviation in response to severe shocks. However, because there is a trade-off between flexibility and credibility, an escape clause must embody a time-bound, transparent transition path back to compliance with the fiscal policy rule.

23 Simulations exclude escape clauses and depend on the calibration of the parameters described in Box 1. 
Figure 2.

Stochastic Simulations of Alternative Fiscal Rules
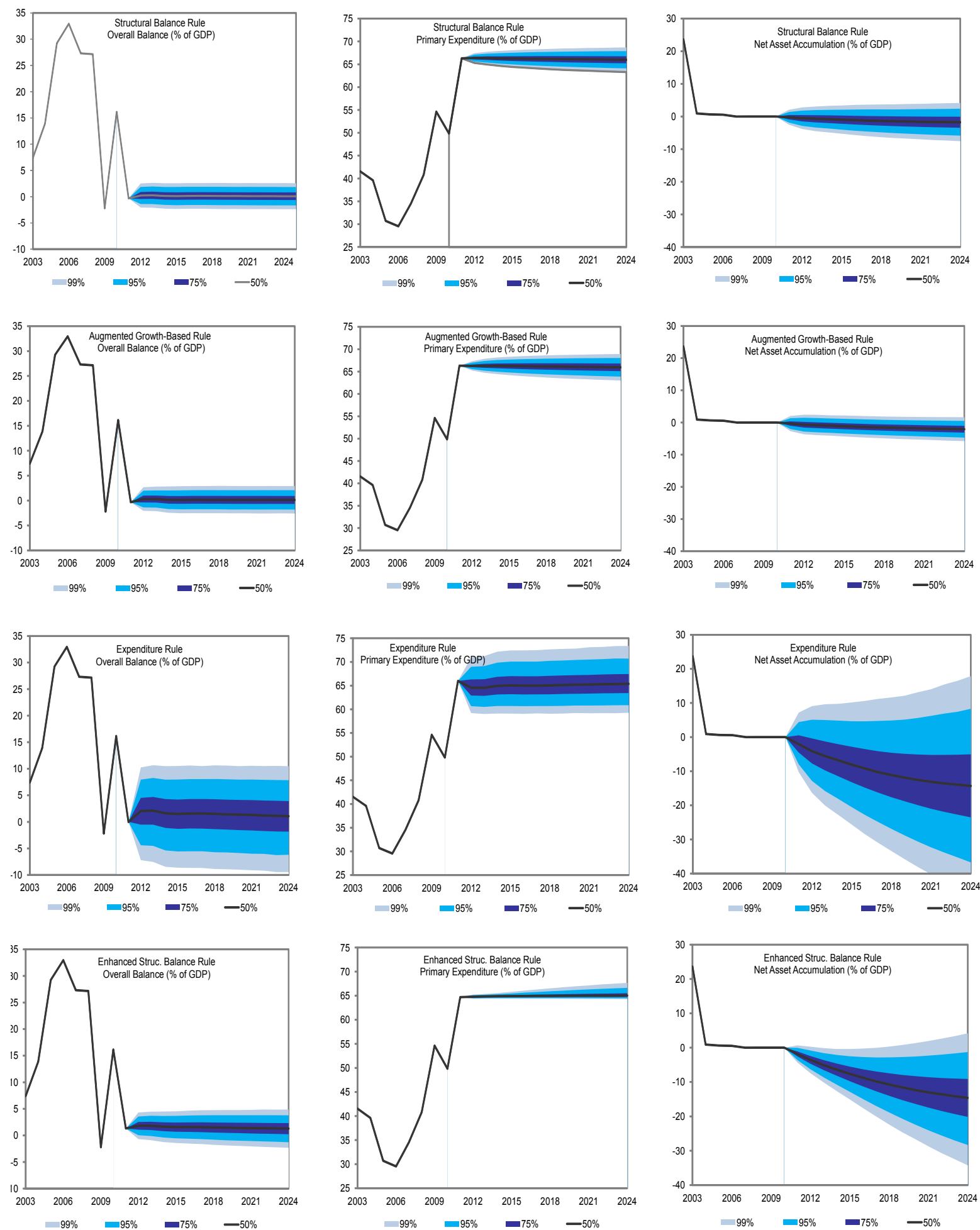

1/ The simulations assume a structural balance target (b*) of zero percent of GDP; long-term real GDP growth of 2.5 percent; a cyclical coefficient (a) of 0.25 for the structural balance and augmented-growth-based rules; a semi-elasticity of the balance-to-GDP ratio (c) of 1.5 for the enhanced structural balance; an adjustment coefficient $(\tau)$ of 0.75 for the augmented growth-based rule; and a semi-elasticity of revenueto-GDP ratio with respect to the output gap of 0.3 and with respect to the commodity price index of 1.6.

Source: Authors' calculations. 


\section{CONCLUSION}

Given Libya's hydrocarbon dependency and the central bank's commitment to the pegged exchange rate regime, fiscal policy remains the main policy instrument for preventing abrupt, outsized fluctuations in domestic demand and thereby maintaining macroeconomic stability. The analysis presented in this paper shows that the fiscal stance had been expansionary prior to the revolution, with the cyclically adjusted nonhydrocarbon primary budget deficit widening from 20.5 percent of nonhydrocarbon potential GDP in 2000 to 225 percent by 2010. Current expenditures increased significantly during and after the conflict primarily because of a sustained rise in the wage bill and subsidies. Although Libya can afford elevated current spending in the short term, the level of recurrent spending is inconsistent with appropriate budgetary prioritization and will lead to an appreciation of the real exchange rate. Assessed according to the present value of future resource extraction and accumulated financial assets, the long-term sustainability of public finances is already questionable, with the nonhydrocarbon primary budget deficit running well above the equilibrium level, even with high oil prices.

Assuming constant real per capita government expenditure that delivers a constant real per capita annuity after the depletion of hydrocarbon resources and crude oil prices at an average of $\$ 80$ per barrel, the nonhydrocarbon primary deficit is estimated to be 12.5 percentage points of GDP higher than its equilibrium value in 2013, with the gap increasing to 20 percentage points by 2018. However, the optimal nonhydrocarbon primary deficit could be below the level prescribed by the PIH framework if the economy has a low level of capital stock. Accordingly, with a modified PIH approach excluding development expenditure that may yield a return on investment equal to the discount rate used in the annuity calculations, we estimate that the nonhydrocarbon primary deficit is 3.4 percentage points of GDP below its equilibrium value in 2013 and remaining at 10 percentage points below the estimated equilibrium threshold by 2018 . While this implies abundant fiscal space to accommodate scaling-up of development expenditure, it does not take into account the institutional and absorptive capacity of the economy. In other words, the pace of scaling-up of development spending may need to be tempered to ensure the efficiency of capital investment, to avoid the risk of inflationary pressures, real exchange rate appreciation and lower nonhydrocarbon output, and to be consistent with the need to accumulate precautionary savings against the volatility of hydrocarbon revenues.

Unless the economy is diversified to create additional sources of revenue, the contraction of fiscal revenue would be steep and would significantly constrain expenditure at that time. Furthermore, although the optimal consumption path determined according to the PIH provides a robust point of reference for fiscal policymaking, the volatility of oil prices and greater uncertainty about future hydrocarbon revenues require additional - precautionary - savings. Larger fiscal buffers, accumulated, for example, during periods of higher oil prices, would reduce the need for sharp fiscal tightening during downturns. Finally, in addition to intergenerational equity and sustainability considerations, the fiscal stance also needs to be guided by the objective of maintaining macro-financial stability, as the pegged exchange rate regime constrains the central bank's ability to conduct countercyclical monetary policy and thereby puts the onus of stabilization on fiscal policy.

Although Libya has practically no debt and an abundant stream of hydrocarbon revenues for the next 100 years, if not longer, government finances remain highly vulnerable to the volatility of international oil prices. Government spending tends to increase significantly during periods of high oil prices and to remain practically unchanged in periods when oil prices fall. Furthermore, the government budget is still fragmented in all its phases, from formulation to execution, overlooking the need to focus on medium- to long-term considerations. This not only reduces the effectiveness of fiscal policy in macroeconomic management, but also prevents the advancement of a strategic approach. Therefore, developing a rule-based medium-term fiscal 
framework and building stronger fiscal institutions including a sound PFM system would enhance the quality and effectiveness of fiscal policies and help deal with uncertainties associated with hydrocarbon dependency. To ensure fiscal sustainability and intergenerational equity, the use of resource revenues can be determined according to a legally binding fiscal policy rule and taking into account the absorptive capacity of the economy and the need for precautionary savings. Accordingly, expenditures from hydrocarbon revenues would be stable, and proceeds in excess of the reference oil price would be transferred to the sovereign wealth fund system to be invested abroad as a long-term saving instrument for future generations, while the stabilization fund would smooth expenditure over the economic cycle.

There is no one-size-fits-all fiscal policy rule that would work always and everywhere, because the effectiveness of rules varies considerably across countries depending on the target variable, the initial conditions, the method of implementation, and the type of shocks that the economy experiences, among other factors. In this paper, we assess the performance of alternative fiscal policy rules by utilizing stochastic simulation methods, which enable us to compare the responses of different fiscal policy rules subject to various macroeconomic shocks. The simulation results suggest that the "enhanced" structural balance rule - taking into account the volatility of commodity prices - would entail the narrowest band for primary spending in response to macroeconomic shocks. The "enhanced" structural balance rule is similar to maintaining the cyclically adjusted nonhydrocarbon balance as a share of nonhydrocarbon GDP constant over time, which can be set according to the level derived from the PIH model used in assessing fiscal sustainability and intergenerational equity. However, although the "enhanced" structural balance rule appears - from a theoretical point of view - to be the strongest anchor for fiscal policy in a country like Libya, institutional capacity constraints may prevent its implementation in the near future.

At this stage, an expenditure rule, taking into account the front-loaded needs for infrastructure spending in the immediate post-revolution period, appears to be the most feasible option to anchor fiscal policy formulation in a medium-term framework, with a view towards transitioning towards the adoption of the "enhanced" structural balance rule. ${ }^{24}$ Even from a medium-term perspective, an appropriately designed expenditure rule can be a complementary limit on the rate of increase in government spending, instituting countercyclical properties in fiscal policy formulation, with a view to ensuring fiscal sustainability and intergenerational equity. Past experience, however, shows that an expenditure rule, like other fiscal policy rules, only works if there is a genuine political commitment to fiscal discipline. Without that commitment, the expenditure rule risks leading to creative accounting and off-budget operations, reducing transparency while failing to genuinely improve the quality of fiscal policy. In this context, Libya would also benefit from establishing an independent fiscal council that would provide independent advice on the structural level of revenues to determine the expenditure envelope and help improve fiscal transparency by reporting on budgetary policy without political influence. ${ }^{25}$

Most countries prefer to codify the rules and institutional arrangements for natural resource management in some form of legislation, with varying degrees of detail. Generally, best practice is to be clear about the objectives, institutions, and reporting arrangements for the management of natural resource wealth, and to safeguard against over-prescription so that the rules and procedures do not come into conflict with wider macro-fiscal objectives and undermine the credibility of the law. Fiscal rules enshrined in the constitution tend to be harder to amend; hence, Libya would benefit from incorporating the basic principles of a rule-based fiscal regime in the forthcoming constitution, with the institutional and operational details described in a fiscal responsibility law.

\footnotetext{
24 The fiscal sustainability analysis presented in this paper does not specifically model the return on public investment, which is assumed to be embedded in the growth projections. Therefore, we make no distinction between capital and current expenditure in terms of productivity gains.

25 Debrun (2011) provides a theoretical assessment of independent fiscal policy councils.
} 


\section{Acknowledgements}

The authors would like to thank Hesham Alogeel, Alberto Behar, Ralph Chami, Reda Cherif, Salvatore Dell'Erba, Kia Penso, and Agustin Roitman, and participants of a presentation at the Central Bank of Libya held on March 7, 2013 for their insightful comments and suggestions. The views expressed herein are those of the authors and should not be attributed to the IMF, its executive Board, or its management.

\section{References}

Abdih, Y., P. Lopez-Murphy, A. Roitman, and R. Sahay, 2010, "The Cyclicality of Fiscal Policy in the Middle East and Central Asia: Is the Current Crisis Different?" IMF Working Paper, No. 10/68 (Washington: International Monetary Fund). DOI: 10.5089/9781451982121.001

Barnett, S., and R. Ossowski, 2002, “Operational aspects of Fiscal Policy in Oil-Producing Countries,” IMF Working Paper, No. 02/177 (Washington: International Monetary Fund). DOI: 10.5089/9781451858884.001

Baunsgaard, T., M. Villafuerte, M. Poplawski-Ribeiro, and C. Richmond, 2012, "Fiscal Frameworks for Resource Rich Developing Countries," IMF Staff Discussion Note, No. 12/04 (Washington: International Monetary Fund).

Baxter, M., and R. King, 1999, "Measuring Business Cycles: Approximate Band-Pass Filters for Economic Time Series," Review of Economics and Statistics, Vol. 81, pp. 573-593. DOI: 10.1162/003465399558454

Bems, R., and I. Carvalho Filho, 2009, "Current Account and Precautionary Savings for Exporters of Exhaustible Resources," IMF Working Paper, No. 09/33 (Washington: International Monetary Fund). DOI: $10.5089 / 9781451871807.001$

Berg, A., R. Portillo, S. Yang, and L. Zanna, 2012, "Public Investment in Resource-Abundant Developing Countries," IMF Working Paper, No. 12/274 (Washington: International Monetary Fund). DOI: $10.5089 / 9781475535563.001$

Budina, N., T. Kinda, A. Schaechter, and A. Weber, 2012, "Fiscal Rules at a Glance: Country Details from a New Dataset," IMF Working Paper, No. 12/187 (Washington: International Monetary Fund). DOI: $10.5089 / 9781616359102.001$

Caceres, C., and M. Ruiz-Arranz, 2010, “What Fiscal Rule Would Work Best for the UK?" IMF Selected Issues Paper, No. 10/337 (Washington: International Monetary Fund).

Celasun, O., X. Debrun, J. Ostry, 2006, "Primary Surplus Behavior and Risks to Fiscal Sustainability in Emerging Market Countries: A 'Fan Chart' Approach,” IMF Working Paper, No. 06/67 (Washington: International Monetary Fund). DOI: 10.5089/9781451863277.001

Cevik, S., 2011, "Policy Coordination in Fiscal Federalism: Drawing Lessons from the Dubai Debt Crisis," IMF Working Paper, No. 11/147 (Washington: International Monetary Fund). DOI: 10.5089/9781455269457.001

Cherif, R., and F. Hasanov, 2012, “Oil Exporters' Dilemma: How Much to Save and How Much to Invest," IMF Working Paper, No. 12/4 (Washington: International Monetary Fund). DOI: 10.5089/9781475502459.001

Debrun, X., 2011, “Democratic Accountability, Deficit Bias and Independent Fiscal Agencies,” IMF Working Paper, No. 11/173 (Washington: International Monetary Fund). DOI: 10.5089/9781462313327.001

Debrun, X., and M. Kumar, 2007, “The Discipline-Enhancing Role of Fiscal Institutions: Theory and Empirical Evidence," IMF Working Paper, No. 07/171 (Washington: International Monetary Fund). DOI: $10.5089 / 9781451867350.001$

Filc, G., and C. Scartascini, 2007, "Budgetary Institutions," in The State of State Reform in Latin America, edited by E. Lora (Washington: Inter-American Development Bank).

Hodrick, R., and E. Prescott, 1997, "Post-War Business Cycles: An Empirical Investigation,” Journal of Money, Credit, and Banking, Vol. 29, pp. 1-16. DOI: 10.2307/2953682

Horton, M., M. Kumar, and P. Mauro, 2009, “The State of Public Finances: A Cross-Country Fiscal Monitor," IMF Staff Position Note, No. 09/21 (Washington: International Monetary Fund).

Kaminsky, G., C. Reinhart, and C. Vegh, 2004, "When It Rains, It Pours: Procyclical Capital Flows and Macroeconomic Policies," NBER Macroeconomics Annual, Vol. 19, pp. 11-82 (Cambridge, MA: National Bureau for Economic Research). DOI: 10.3386/w10780

Kopits, G., and S. Symansky, 1998, “Fiscal Policy Rules,” IMF Occasional Paper, No. 162 (Washington: International Monetary Fund). 
Kumar, M., E. Baldacci, A. Schaechter, C. Caceres, D. Kim, X. Debrun, J. Escolano, J. Jonas, P. Karam, I. Yakadina, and R. Zymek, 2009, "Fiscal Rules - Anchoring Expectations for Sustainable Public Finances,” IMF Policy Paper, No. 09/274 (Washington: International Monetary Fund).

Leland, H., 1968, "Saving and Uncertainty: The Precautionary Demand for Saving," Quarterly Journal of Economics, Vol. 82, pp. 465-473. DOI: 10.2307/1879518

Medas, P., and D. Zakharova, 2009, "Primer on Fiscal Analysis in Oil-Producing Countries," IMF Working Paper, No. 09/56 (Washington: International Monetary Fund). DOI: 10.5089/9781451872033.001

Ravn, M., and H. Uhlig, 2002, "On Adjusting the Hodrick-Prescott Filter for the Frequency of Observations," Review of Economics and Statistics, Vol. 85, pp. 235-243. DOI: 10.1162/003465302317411604

Rogoff, K., 1990, “Equilibrium Political Budget Cycles,” NBER Working Paper, No. 2428 (Cambridge, MA: National Bureau for Economic Research). DOI: 10.3386/w2428

Talvi, E., and C. Vegh, 2005, “Tax Base Variability and Procyclicality of Fiscal Policy,” Journal of Development Economics, Vol. 78, pp. 156-190. DOI: 10.1016/j.jdeveco.2004.07.002

Ter-Minassian, T., 2006, "Fiscal Rules for Subnational Governments: Can They Promote Fiscal Discipline," OECD Journal on Budgeting, Vol. 6, pp. 111-121. DOI: 10.1787/budget-v6-art17-en

Villafuerte, M., P. Lopez-Murphy, and R. Ossowski, 2010, "Riding the Roller Coaster: Fiscal Policies of Nonrenewable Resource Exporters in Latin America and the Caribbean,” IMF Working Paper, No. 10/251 (Washington: International Monetary Fund). DOI: 10.5089/9781455209514.001 